\title{
Experimental Study on the Influence of Soil Structure Index on Loess Permeability
}

\author{
Feng Yue $\mathbb{D},{ }^{1}$ Xin Ren, ${ }^{1}$ Xuelang Wang, ${ }^{1}$ and Wentong Tian $\mathbb{D}^{2}$ \\ ${ }^{1}$ Western Centre of Disaster Mitigation in Civil Engineering, Ministry of Education Lanzhou University of Technology, \\ Lanzhou 730050, China \\ ${ }^{2}$ Key Laboratory of Loess Earthquake Engineering, Lanzhou Institute of Seismology CEA, Lanzhou 730030, China \\ Correspondence should be addressed to Feng Yue; yuefeng_666@163.com
}

Received 15 December 2021; Accepted 25 January 2022; Published 9 February 2022

Academic Editor: Yonghong Wang

Copyright (C) 2022 Feng Yue et al. This is an open access article distributed under the Creative Commons Attribution License, which permits unrestricted use, distribution, and reproduction in any medium, provided the original work is properly cited.

In order to study the effects of dry density and initial water content on the permeability characteristics of loess, the saturated permeability tests of undisturbed loess and remolded loess were carried out in Lanzhou New Area. The anisotropy of undisturbed loess under two factors is analyzed and compared, and the permeability difference between undisturbed loess and remolded loess is also analyzed. The results show that the structure of loess has an important impact on the permeability characteristics, and the dry density is an important structural parameter. The natural structure of undisturbed loess has obvious anisotropy. Under different pore conditions and water contents, it will show the anisotropic behavior of permeability. The influence of water content on permeability is mainly reflected in the influence on the properties of cement between soil particle skeletons. Under different dry density conditions, the influence of water content on permeability is different. When the pore structure is relatively compact, the influence of water content is more obvious. In practical engineering, these two factors need to be comprehensively considered in order to accurately describe the permeability distribution of loess. This study can provide some theoretical guidance for the construction of relevant loess projects.

\section{Introduction}

Loess is widely distributed in western China, of which Lanzhou belongs to the Loess Plateau, with a large thickness and wide distribution range. With the continuous development of urban construction and infrastructure, the engineering construction in this area has to face a series of engineering problems caused by the special nature of loess. Engineering problems and geological disasters induced by loess have caused great economic losses and waste of resources and affected the local economic development to a certain extent. The properties of loess are affected by genesis, geological age, and climate, which makes loess have special physical and mechanical properties. On the one hand, loess has a macroporous structure, the soil structure is obvious, and the structure between loess particles determines the basic properties of loess. On the other hand, loess also has strong water sensitivity, which will lead to the change in pore structure after encountering water, resulting in the problems of strength, permeability, and collapsibility. Water has an important influence on the strength of the soil. The existence of water reduces the occlusal ability between particles and leads to the reduction in the internal friction angle of the soil. Moreover, the increase in pore water will reduce the contact degree between particles and reduce the cohesion of the soil. Due to the special structure and water sensitivity of loess, the impact of the water environment on loess is more intense and obvious. The permeability of the soil is closely related to the pore channel between soil particles, but the water sensitivity of loess makes the structure of loess change when it meets water, resulting in the change of permeability. The study of permeability is the premise of the study of seepage field. Reasonable description and determination of loess permeability can provide technical support for the determination of loess antiseepage engineering measures. Therefore, exploring the relationship between loess structure and permeability has important theoretical and application value. 
This problem has also attracted the attention of many scholars, and a large number of experiments and theoretical research have been carried out. For the special physical and mechanical properties of loess, many scholars have carried out fruitful research. Loess structure has a great impact on the mechanical behavior of loess. The consistent impact of metastable structure on the mechanical properties of loess is the core hotspot of researchers. Through the comparative experimental study of undisturbed soil and remolded soil, Bao-Ping and Ya-Jing [1] pointed out that the peak strength and strength parameters of loess are closely related to the structure, and the influence of loess structure on cohesion is more obvious. The structure of loess not only affects the soil strength but also is closely related to the collapsibility of loess. Pan et al. [2] found that the collapsibility curve of loess can be divided into three stages. This research result provides a new idea and method for the description of structural parameters. The study of Fu et al. [3] shows that the natural soil structure has a significant impact on the compressibility, dilatancy, and shear strength of loess, and the constitutive model of saturated loess based on the test provides a new method for determining the initial degree of structure. There are obvious differences in structure between intact soil and remolded soil. The destruction and remodeling of natural structure will have a significant impact on the strength of soil, and the strength of the intact soil is significantly higher than that of the remolded soil. The size of soil particles will affect the compressibility of soil. The structure will not only affect the strength of loess but also affect the anisotropic behavior of loess [4-7]. The collapsibility of loess is one aspect of loess structure and water sensitivity. The loess structure changes after encountering water, and the occurrence of loess collapsibility changes the stress field of the engineering structure, resulting in engineering problems, which cannot be ignored. Li et al. [8] carried out this research and pointed out that, in loess tunnel engineering, loess collapse will lead to the increase of base pressure and the cracking of tunnel invert. In addition, the location of collapse will also affect the mechanical properties of the tunnel. With the increase of infiltration range, the failure will gradually develop from the arch foot to near the inverted arch [9]. In order to ensure the safety of engineering construction in loess areas, improving the properties of loess is an essential process. The structure of loess largely determines the mechanical properties of loess. Therefore, based on this idea, some scholars use chemical treatment methods to try to change the structural characteristics of loess, so as to improve the mechanical properties of loess. The use of acid solution can effectively destroy the macropore structure of loess, and the loess treated with acid solution has a smaller pore ratio than natural loess [10]. $\mathrm{SiO}_{2}$ nanoparticles as additives can also effectively improve the properties of loess [11]. In more extreme environments, the freeze-thaw cycle will accelerate the damage of the loess pore structure, resulting in the reduction of loess compressibility and strength. After the freeze-thaw cycle, the performance of loess with lime is obviously due to natural loess [12].
Loess has strong structural performance. At the meso level, the characteristics of pore structure control the permeability to a great extent, and the permeability research has an important impact on engineering construction [13]. The permeability of loess also has obvious anisotropic behavior. There are great differences in structural characteristics between undisturbed loess and remolded loess. Therefore, its permeability will also show obvious differences. The structure of loess is different at different depths, and the anisotropy of infiltration along the depth direction is stable $[14,15]$. The pore structure of compacted loess changes, and the horizontal permeability coefficient will be greater than the vertical permeability coefficient. There is a close relationship between dry density and permeability [16, 17]. The stress environment, temperature, and plant roots around loess will have a certain impact on permeability $[18,19]$. On the one hand, the change in temperature will affect the viscosity of water, on the other hand, it may affect the soil structure, and the overall permeability will increase with the increase of temperature [20]. Ions in pore water will cause the dissolution of structural media, thus changing pore characteristics and increasing permeability coefficient [21]. The existence of plant roots will fill the macropore structure in loess, resulting in a significant reduction in permeability [22]. In addition, some scholars have done a lot of research on the structure of loess and the coupling of various external factors, and combined with the analysis of experimental data, they have given some very useful theories [23-29]. The proposal of these theoretical models provides an important supporting role for exploring the properties of loess.

The above research results greatly promote people's understanding of loess structural characteristics and permeability and provide theoretical and technical support for the solution of loess engineering problems. However, loess is widely distributed, and the pore characteristics of loess in different regions are quite different. More experimental research is needed to improve and supplement the research results of this problem. In practical engineering, when seepage or seepage consolidation occurs, the loess is actually in a saturated state. Therefore, further exploring the relationship between loess structural index and loess saturated permeability coefficient has better practical value. This paper makes an experimental study on this problem and explores the relationship between natural structure and permeability by studying the permeability of undisturbed loess under different moisture contents and dry densities. Secondly, the permeability test of the remolded loess is carried out, and the influence laws of initial water content and dry density of the remolded loess on loess permeability are given.

\section{Materials and Methods}

In this paper, the effects of water content and dry density of loess on permeability are studied. The permeability tests of intact loess and remolded loess samples with different water contents were carried out, respectively. The loess particle size is small, so the permeability test is carried out by the variable water head method. 
2.1. Materials. The loess required for the test is taken from Lanzhou New Area, the site is shown in Figure 1, and the soil is $\mathrm{Q}_{3}$ loess. After the intact loess is sampled, the basic physical parameters are measured. The remolded soil samples are prepared according to the test scheme after drying and crushing the intact loess.

2.1.1. Soil Sample Information. Four groups of undisturbed soil were collected on site, and the sampling of undisturbed soil samples is shown in Figure 2. Undisturbed soil samples were divided into 4 groups according to different dry densities. Each group contains three samples with different moisture contents. The dry density of group IA is about $1.25 \mathrm{~g} / \mathrm{cm}^{3}$, that of group IB is about $1.35 \mathrm{~g} / \mathrm{cm}^{3}$, and that of group IC and ID is $1.41 \mathrm{~g} / \mathrm{cm}^{3}$ and $1.6 \mathrm{~g} / \mathrm{cm}^{3}$, respectively. In order to compare the effects of different water contents on the permeability of undisturbed loess, three samples in each group have different water contents, which are recorded as No. 1, No. 2, and No. 3, respectively. After sampling, the initial moisture content of the undisturbed soil shall be measured, and then, the sample shall be formed. The target moisture content shall be adjusted according to the scheme, and the moisture content of the undisturbed sample shall be changed by spraying. The grouping and basic information of undisturbed soil samples are shown in Table 1, and the particles of soil for the test are shown in Figure 3.

The remolded soils were prepared by drying and crushing the loess in its original form. The effects of water content and dry density on the permeability of loess were considered in the test. The dry density of the three specimens in RA was about $1.25 \mathrm{~g} / \mathrm{cm}^{3}$, the dry density of the specimens in $\mathrm{RB}$ was about $1.35 \mathrm{~g} / \mathrm{cm}^{3}$, and the dry density of the specimens in RC and RD was about $1.41 \mathrm{~g} / \mathrm{cm}^{3}$ and $1.61 \mathrm{~g} /$ $\mathrm{cm}^{3}$, respectively. Three specimens with different water contents were included in each group, and the specimens were recorded as 1, 2, and 3, respectively. The basic parameters of the remolded soil specimens are shown in Table 2.

2.1.2. Test Instruments. The saturation penetration instrument is required for the penetration test. TST-55 saturation penetration instrument is used in this test, and the thermometer is used to measure indoor temperature. A sample preparation device is required for the preparation of reshaped samples, and a ring knife is required in the sample forming process. Aluminum box, oven, and electronic scale can be used for the determination of soil moisture content, in which the accuracy of electronic scale needs to reach $0.01 \mathrm{~g}$.

2.2. Methods. Permeability test of undisturbed soil: firstly, after the undisturbed soil is retrieved, the moisture content is tested to determine the moisture content, the wet density and dry density of the sample are measured, and the particle analysis test of the soil sample is carried out to determine the particle size distribution information of the test loess. Second, undisturbed soil samples with different moisture contents shall be configured, and the original moisture content shall be used as the basis. Another two samples with different moisture contents shall be configured under the same dry density. According to the information in Table 1, ensure that each group contains three undisturbed soil samples. Third, process each sample so that the diameter of the sample is $61.8 \mathrm{~mm}$ and the height is $40 \mathrm{~mm}$, and the sample photos are shown in Figure 4(a). Wipe Vaseline on the inner wall of the sleeve, put in the soil sample ring knife, and ensure that the water head height is not higher than $2 \mathrm{~m}$, so as to prevent the seepage force generated by an excessive hydraulic gradient from damaging the sample. Stand still to saturate the soil sample, and observe and record the rising speed of water in the sample. After the sample is completely saturated, the permeability coefficient is measured.

Remolded soil permeability test: after the undisturbed soil sample is crushed and dried, the moisture content shall be adjusted first, and the moisture content shall be configured according to Table 2. After the water content is configured, the soil sample shall stand for $24 \mathrm{~h}$ to ensure uniform water content distribution of the soil sample. Then, the samples with different dry densities are prepared, and the sample preparation device is used to sample the remolded soil. The sample diameter is $61.8 \mathrm{~mm}$ and the height is $40 \mathrm{~mm}$, and the remolded soil sample photos are shown in Figure 4(b). The procedure of the saturated permeability test is consistent with that of intact soil.

\section{Test Results}

The results of the permeability test of undisturbed soil and remolded soil are shown in Table 3. The vertical permeability and horizontal permeability of undisturbed soil were measured, and only the vertical permeability of remolded soil was measured. Figure 5 shows the histogram of the permeability coefficient of each intact soil test group. The dry density of the three samples in each group is basically the same, but their moisture content is different.

For intact soil, the vertical permeability coefficient and horizontal permeability coefficient will decrease with the increase of dry density. In general, the vertical permeability coefficient of the sample is greater than the horizontal permeability coefficient. This phenomenon occurs under different dry densities, as shown in Figure 5. In undisturbed soil samples, when the dry density is $1.25 \mathrm{~g} / \mathrm{cm}^{3}$, the vertical permeability coefficient is between $3.5 \times 10^{-5} \mathrm{~m} / \mathrm{s}$ and $3.9 \times 10^{-5} \mathrm{~m} / \mathrm{s}$, and the average value is $3.7 \times 10^{-5} \mathrm{~m} / \mathrm{s}$. When the dry density is about $1.35 \mathrm{~g} / \mathrm{cm}^{3}$, the average permeability coefficient of the three samples is $1.9 \times 10^{-5} \mathrm{~m} / \mathrm{s}$, and when the dry density increases to about $1.60 \mathrm{~g} / \mathrm{cm}^{3}$, the average value is $1.07 \times 10^{-5} \mathrm{~m} / \mathrm{s}$.

Loess has obvious characteristics of vertical macropore structure, which makes a significant difference between vertical and horizontal permeability coefficients. The anisotropy of pore structure is related to the natural origin of loess. Under different pore structures, it will show various anisotropic behaviors of permeability. In IA, IC, and ID, the ratio of $k_{v}$ to $k_{h}$ increases with the increase of water content, but in IB, the ratio of $k_{v}$ to $k_{h}$ decreases with the increase of water content (see Figure 6(a)). The distribution of the 


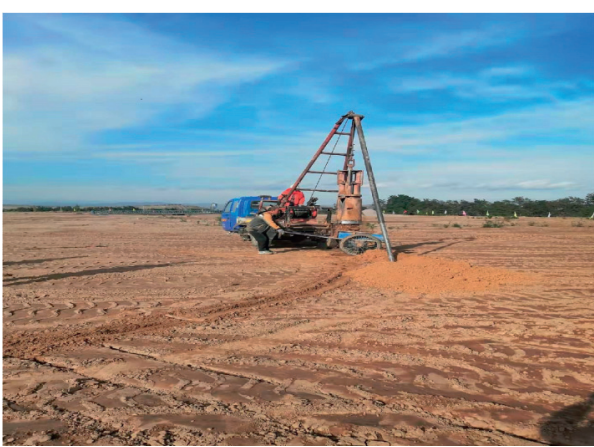

(a)

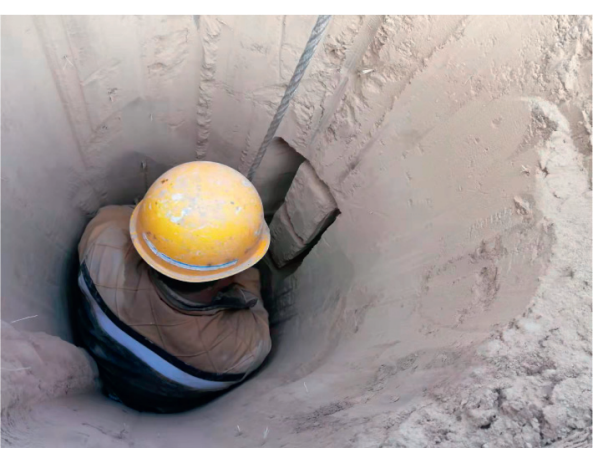

(b)

FIGURE 1: Sampling process of soil sample. (a) Borrow site. (b) Sampling location.

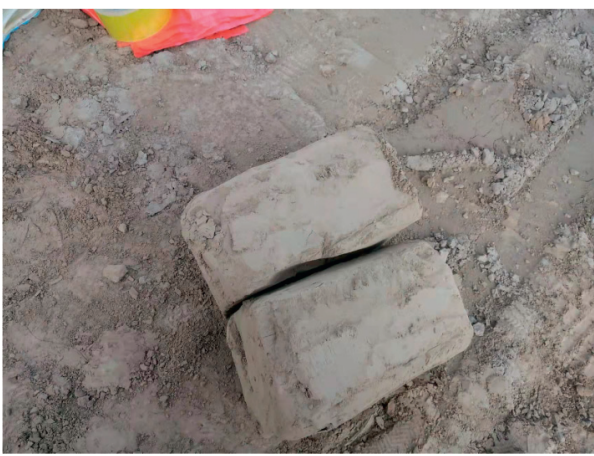

(a)

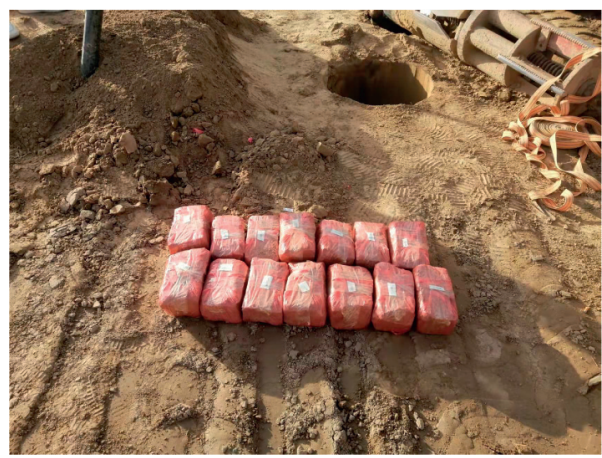

(b)

Figure 2: Photos of intact loess sampling. (a) Intact soil photos. (b) After intact loess sampling.

TABLE 1: Intact loess sample parameters.

\begin{tabular}{lccc}
\hline Group & Moisture content $(\%)$ & Density $\left(\mathrm{g} / \mathrm{cm}^{3}\right)$ & Dry density $\left(\mathrm{g} / \mathrm{cm}^{3}\right)$ \\
\hline IA1 & 4.50 & 1.35 & 1.24 \\
IA2 & 9.80 & 1.39 & 1.26 \\
IA3 & 12.60 & 1.40 & 1.24 \\
IB1 & 11.00 & 1.46 & 1.33 \\
IB2 & 15.70 & 1.51 & 1.34 \\
IB3 & 19.80 & 1.61 & 1.37 \\
IC1 & 8.40 & 1.54 & 1.42 \\
IC2 & 14.10 & 1.61 & 1.41 \\
IC3 & 22.50 & 1.73 & 1.41 \\
ID1 & 8.80 & 1.73 & 1.59 \\
ID2 & 9.80 & 1.76 & 1.61 \\
ID3 & 14.70 & 1.86 & 1.62 \\
\hline
\end{tabular}

permeability coefficient of the remolded soil sample is shown in Figure 6(b). On the whole, the permeability coefficient decreases with the increase of dry density.

\subsection{Effect of Initial Water Content on Permeability.} Figure 7 shows the relationship curve between permeability coefficient and water content of undisturbed soil under each group. In IA, the dry density of the sample is about $1.25 \mathrm{~g} / \mathrm{cm}^{3}$, and the corresponding moisture content is $4.50 \%, 9.70 \%$, and $17.60 \%$, respectively. When the water content is below $10 \%$, the variation range of soil permeability coefficient is small, while when the initial water content is greater than $10 \%$, the vertical permeability coefficient and horizontal permeability coefficient will rise, which is also reflected in IB. In general, with the increase of water content, the vertical and horizontal permeability coefficients in IA and IB will first decrease slightly and then increase. When the dry density is large, such as IC and ID, and the dry density is about $1.40 \mathrm{~g} / \mathrm{cm}^{3}$ and $1.60 \mathrm{~g} / \mathrm{cm}^{3}$, respectively, the permeability coefficients in both directions will decrease with the increase of water content. Moreover, the greater the 


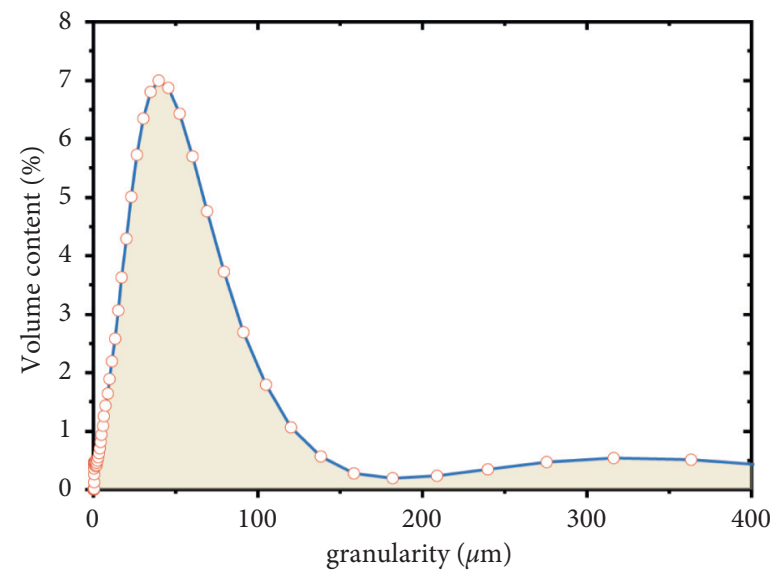

Figure 3: Soil particle size distribution.

TABLE 2: Grouping and parameters of remolded soil samples.

\begin{tabular}{lccc}
\hline Group & Moisture content $(\%)$ & Density $\left(\mathrm{g} / \mathrm{cm}^{3}\right)$ & Dry density $\left(\mathrm{g} / \mathrm{cm}^{3}\right)$ \\
\hline RA1 & 4.50 & 1.31 & 1.25 \\
RA2 & 9.70 & 1.37 & 1.25 \\
RA3 & 17.60 & 1.47 & 1.25 \\
RB1 & 7.60 & 1.43 & 1.33 \\
RB2 & 11.00 & 1.48 & 1.33 \\
RB3 & 19.80 & 1.62 & 1.36 \\
RC1 & 8.90 & 1.54 & 1.41 \\
RC2 & 15.50 & 1.63 & 1.41 \\
RC3 & 22.00 & 1.72 & 1.41 \\
RD1 & 8.20 & 1.74 & 1.61 \\
RD2 & 10.00 & 1.77 & 1.61 \\
RD3 & 14.70 & 1.82 & 1.59 \\
\hline
\end{tabular}

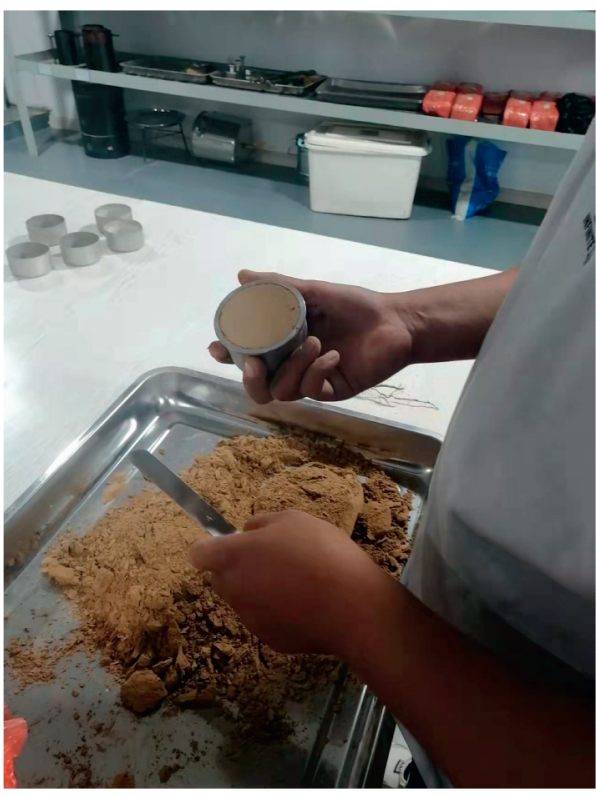

(a)

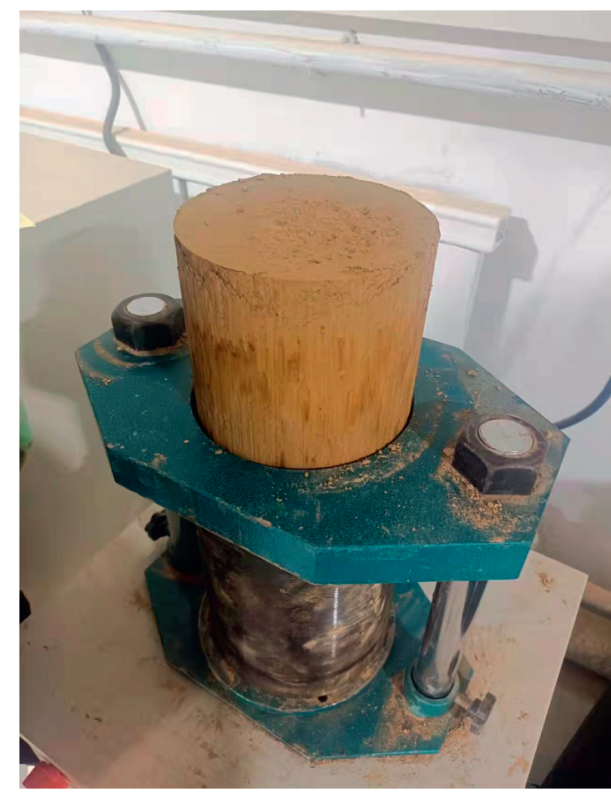

(b)

FIgUre 4: Permeability test specimens. (a) The intact soil specimens. (b) The remolded soil specimens. 
TABLE 3: Permeability coefficient of samples.

\begin{tabular}{lcccc}
\hline Group & $k_{v}(\mathrm{~m} / \mathrm{s})$ & $k_{h}(\mathrm{~m} / \mathrm{s})$ & Group & $k_{v}(\mathrm{~m} / \mathrm{s})$ \\
\hline IA1 & $3.62 \times 10^{-5}$ & $2.96 \times 10^{-5}$ & RA1 & $2.20 \times 10^{-5}$ \\
IA2 & $3.55 \times 10^{-5}$ & $2.97 \times 10^{-5}$ & RA2 & $4.04 \times 10^{-5}$ \\
IA3 & $3.91 \times 10^{-5}$ & $3.57 \times 10^{-5}$ & RA3 & $2.79 \times 10^{-5}$ \\
IB1 & $1.45 \times 10^{-5}$ & $1.87 \times 10^{-5}$ & RB1 & $7.56 \times 10^{-6}$ \\
IB2 & $1.16 \times 10^{-5}$ & $1.13 \times 10^{-5}$ & RB2 & $1.93 \times 10^{-5}$ \\
IB3 & $3.09 \times 10^{-5}$ & $2.34 \times 10^{-5}$ & RB3 & $8.76 \times 10^{-6}$ \\
IC1 & $2.03 \times 10^{-5}$ & $1.95 \times 10^{-5}$ & RC1 & $6.32 \times 10^{-6}$ \\
IC2 & $1.01 \times 10^{-5}$ & $1.48 \times 10^{-5}$ & RC2 & $5.54 \times 10^{-6}$ \\
IC3 & $1.61 \times 10^{-6}$ & RC3 & $4.32 \times 10^{-6}$ \\
ID1 & $2.30 \times 10^{-6}$ & $1.83 \times 10^{-5}$ & RD1 & $1.58 \times 10^{-6}$ \\
ID2 & $6.62 \times 10^{-7}$ & $3.39 \times 10^{-5}$ & RD2 & $1.29 \times 10^{-7}$ \\
ID3 & $2.40 \times 10^{-7}$ & $4.39 \times 10^{-7}$ & RD3 & $2.83 \times 10^{-7}$ \\
\hline
\end{tabular}
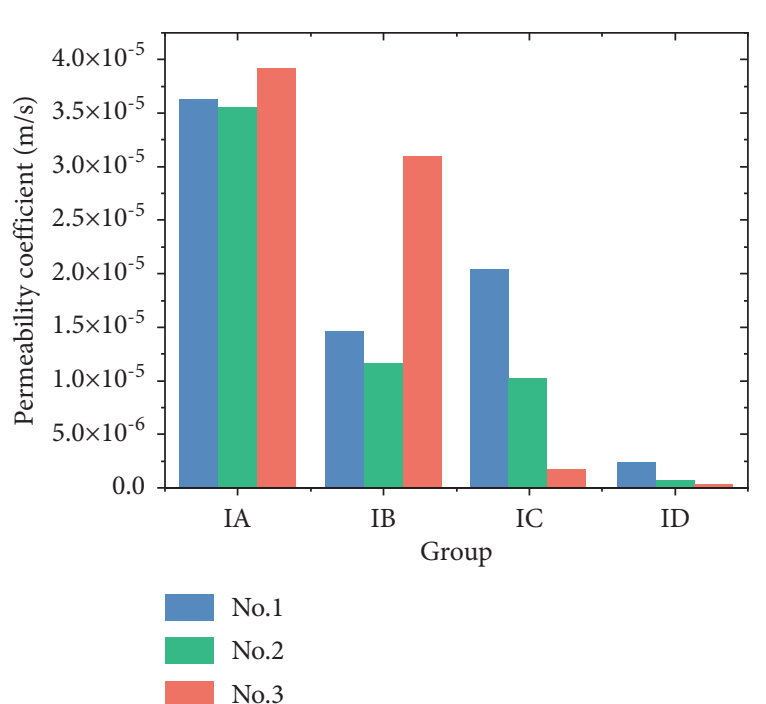

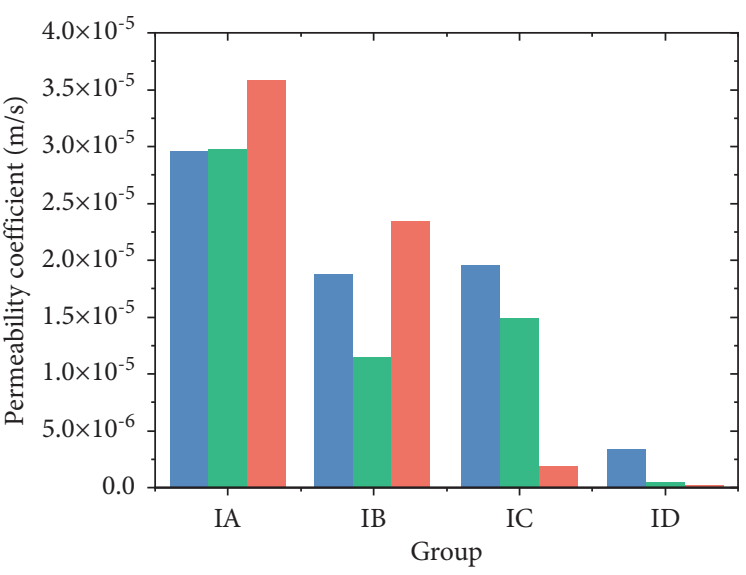

No.1

No. 2

No.3

(a)

(b)

FIgUre 5: Permeability coefficient of intact loess. (a) The vertical permeability coefficient. (b) The horizontal permeability coefficient.

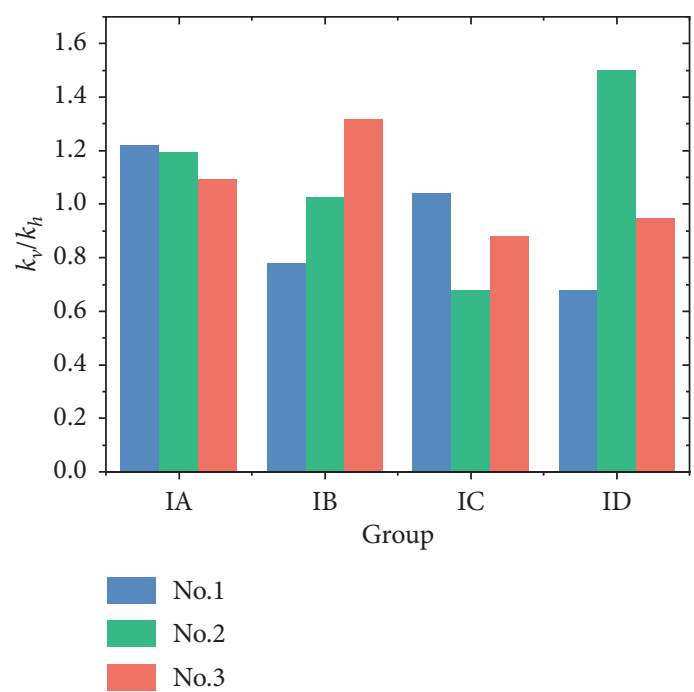

(a)

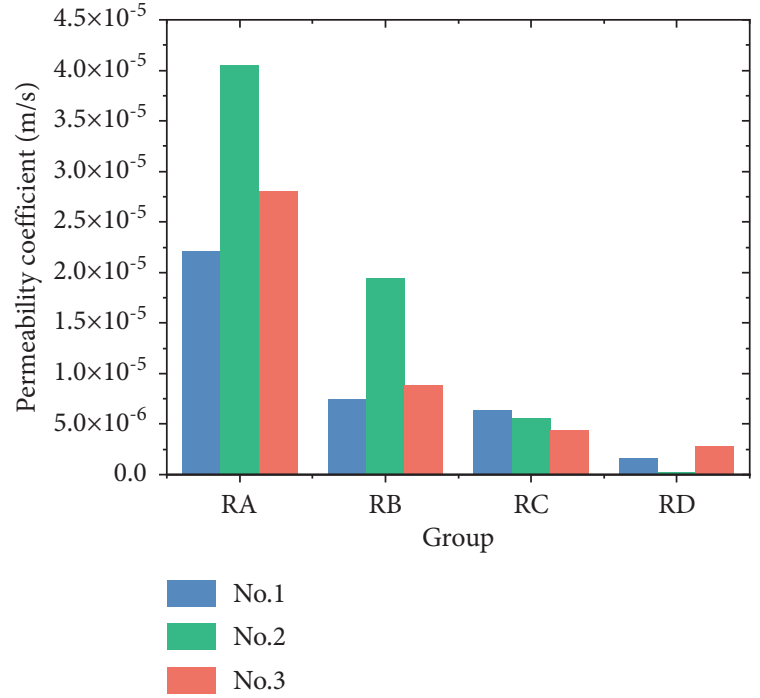

(b)

Figure 6: Permeability histogram. (a) The permeability anisotropy of intact loess. (b) The permeability coefficient of remolded loess. 


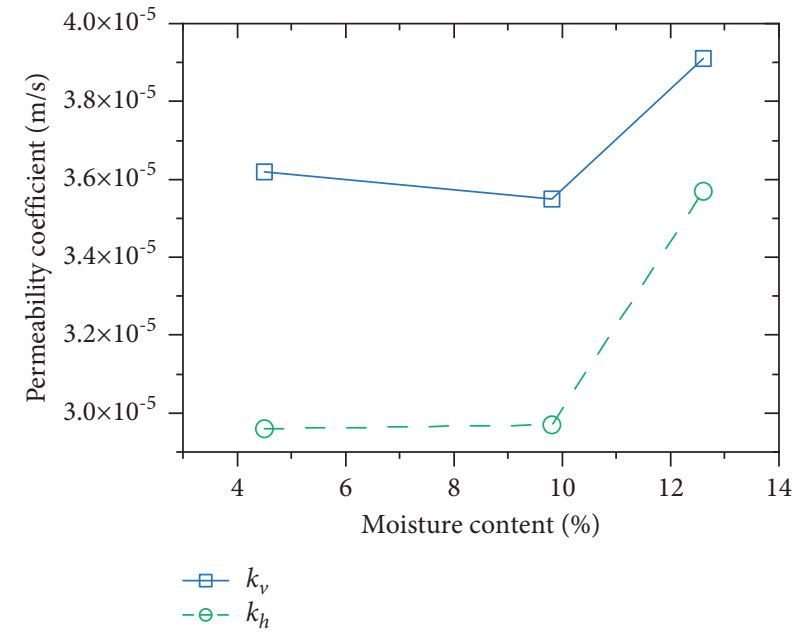

(a)

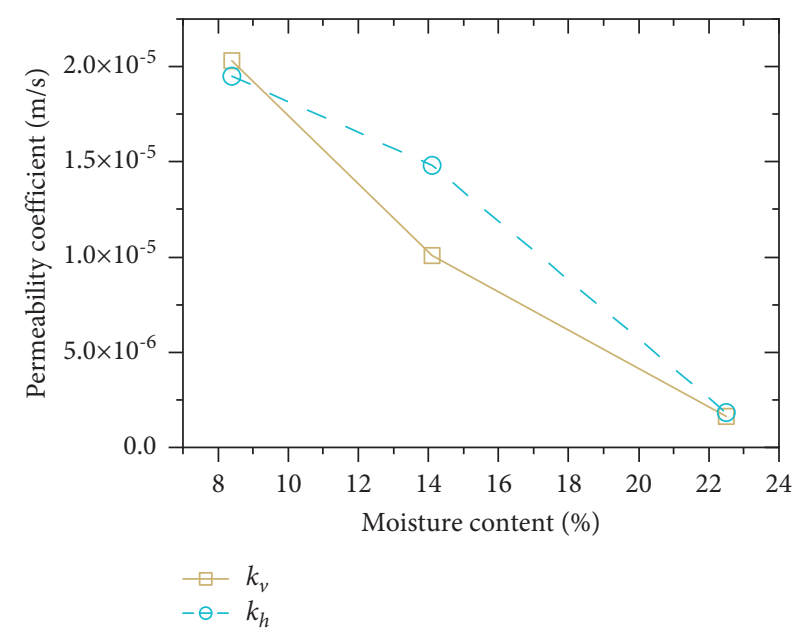

(c)

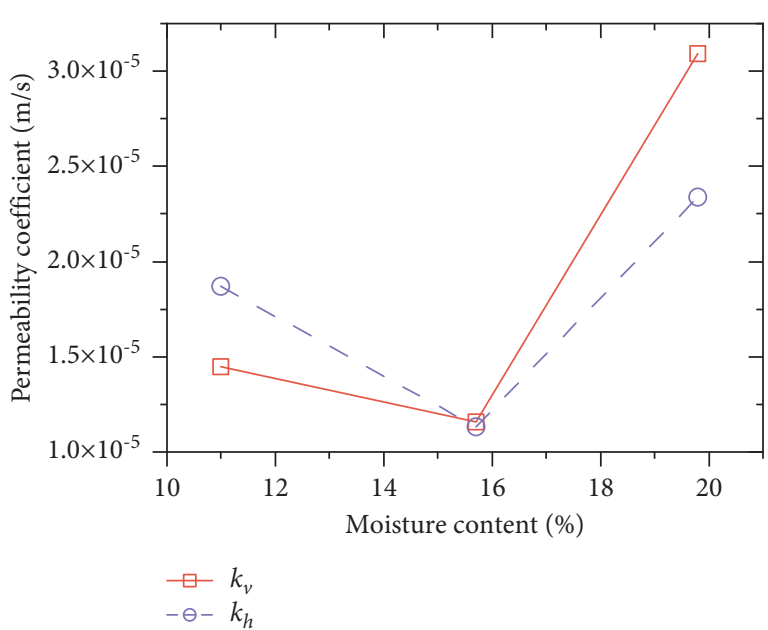

(b)

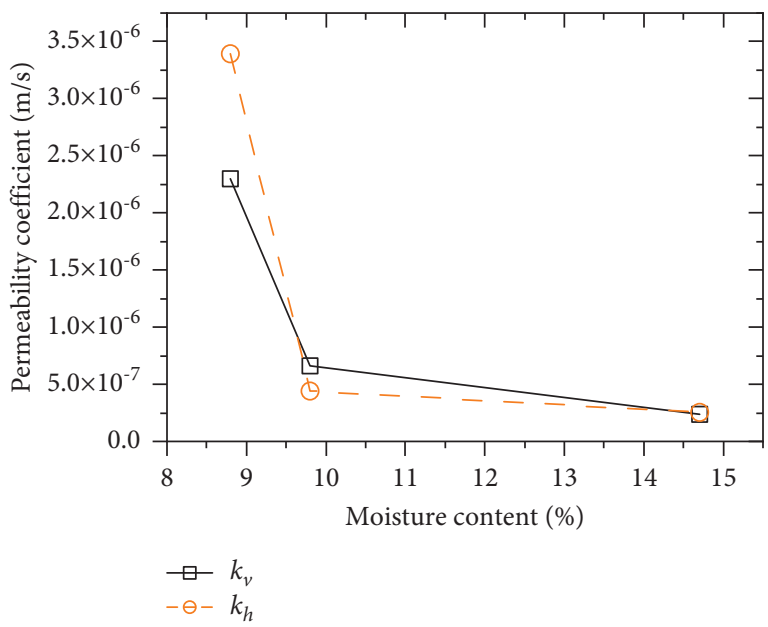

(d)

FIGURE 7: Relation curve between permeability coefficient and water content of undisturbed loess. (a) Group IA. (b) Group IB. (c) Group IC. (d) Group ID.

dry density, the greater the reduction range of permeability coefficient in the lower water content range. When the water content is large, the variation range of permeability coefficient with water content is small. At this time, the pore structure of the soil is mainly affected by dry density.

Figure 8 shows the variation curve of permeability coefficient of remolded soil with water content. When the dry density of the sample in RA is $1.25 \mathrm{~g} / \mathrm{cm}^{3}$ and the water content is $4.50 \%$, the permeability coefficient is $2.20 \times 10^{-5} \mathrm{~m} / \mathrm{s}$. When the water content increases to $9.70 \%$, the permeability coefficient also increases. At this time, if the water content continues to increase, the permeability coefficient will decrease. The dry density of the soil in RB is about $1.35 \mathrm{~g} / \mathrm{cm}^{3}$, and the permeability coefficient curve also shows a similar change trend. In remolded soil samples, when the dry density increases to $1.41 \mathrm{~g} / \mathrm{cm}^{3}$, the permeability coefficient of remolded soil decreases with the increase of water content, and the permeability coefficient at $22.50 \%$ water content is about 1.463 times that at $8.40 \%$. When the dry density continues to increase, the dry density of the sample in $\mathrm{RD}$ is about $16.10 \mathrm{~g} / \mathrm{cm}^{3}$. At this time, the permeability coefficient will first decrease and then increase with the increase of water content. In remolded soil, the influence of water content on permeability coefficient is different under different dry densities.

Dry density represents the tightness between soil pore structures and reflects the structural characteristics of loess to a certain extent, and water content will also affect the pore structure of the soil. Figure 9 shows the scatter diagram of permeability coefficient and water content of undisturbed soil and remolded soil, respectively. Figure 9(a) shows that, under different dry densities, the increase of water content will reduce the vertical saturated permeability coefficient of loess. And the greater the dry density, the lower the permeability. Figure $9(\mathrm{~b})$ shows that the moisture content of remolded soil will affect the permeability of loess to a certain extent under the same dry density.

In essence, the permeability of loess is affected by the pore structure of loess. The water content will change the properties of cement in the soil, and the pore structure will 


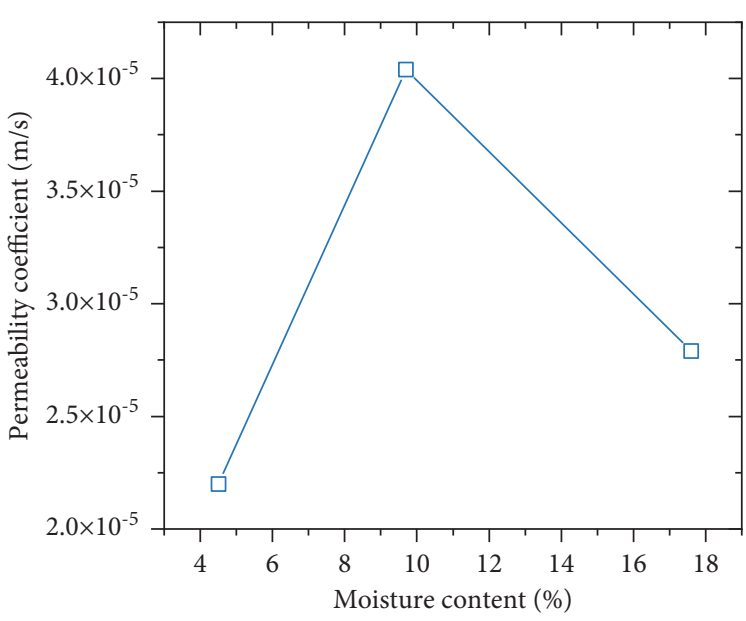

(a)

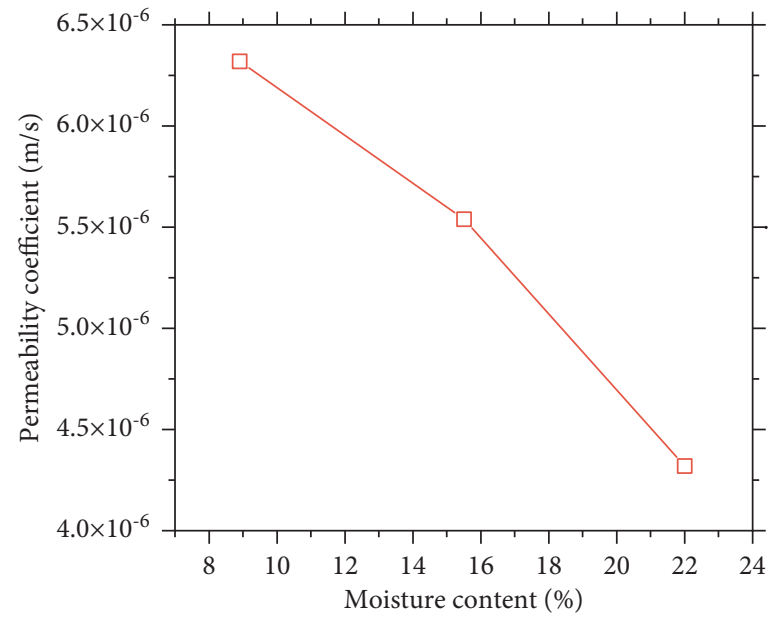

(c)

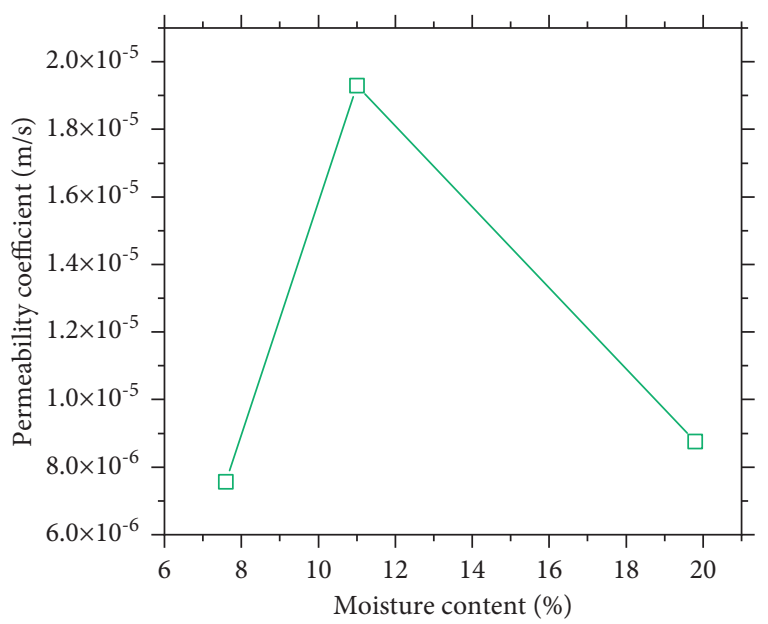

(b)

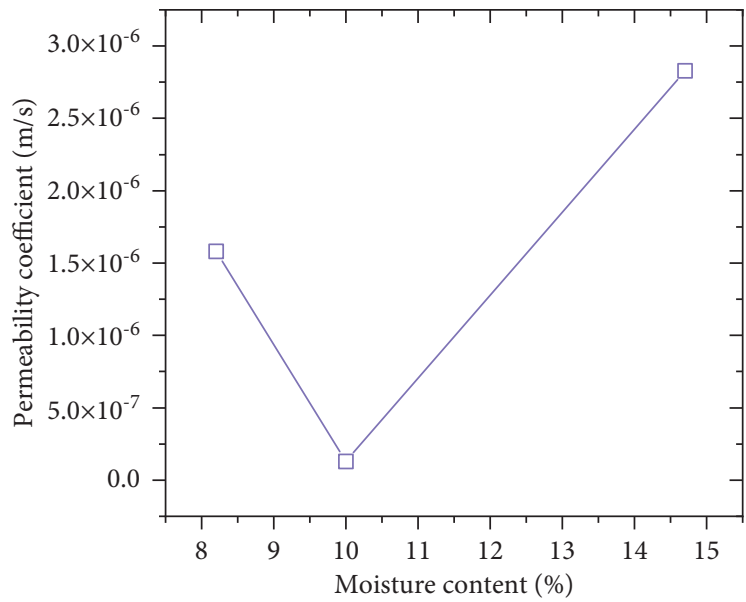

(d)

FiguRE 8: Relation curve between permeability coefficient and water content of the remolded loess. (a) Group RA. (b) Group RB. (c) Group RC. (d) Group RD.

be different under different water contents. The mineral composition of loess is mainly kaolinite, illite, and montmorillonite. Kaolinite is the skeleton particle of loess pore structure, while illite and montmorillonite are attached around the skeleton particle in the form of cement. The skeleton shape between soil particles and the properties of fillers between skeletons determine the distribution state of the loess structure, which makes it have special hydraulic properties. In undisturbed soil, the natural pore structure has not been damaged. Different water content states mainly lead to the properties of cement, resulting in the change of effective seepage channel, and then lead to the change of loess permeability coefficient. In the permeability test of remolded soil, the natural structure of the soil is damaged, and the pore structure will be reformed in the compaction process. The influence law of water content on permeability is different under different dry densities.
3.2. Effect of Dry Density on Permeability. Dry density is an important parameter to characterize the compactness of soil pore structure, which affects the distribution of effective seepage channels to a great extent. Figure 10 shows the relationship between permeability coefficient and dry density when the water content is $10 \%$ and $15 \%$. When the water content is about $10 \%$, the vertical and horizontal permeability coefficients of the intact loess decrease with the increase of dry density. When the dry density is low, the pore structure is relatively loose. At this time, the dry density has a great impact on the permeability and the curve changes greatly. When the moisture content is about $15 \%$, the permeability coefficients in both directions also show a trend of decreasing with the increase of dry density. Figure 11 shows the relationship curve between the permeability coefficient and dry density of the remolded loess. The curve change trend under different water contents is relatively 

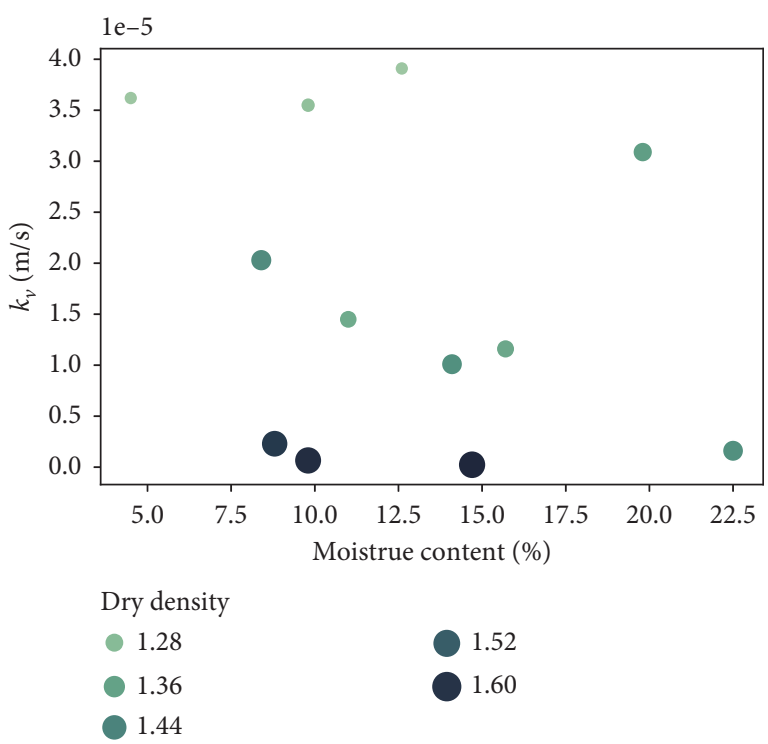

(a)

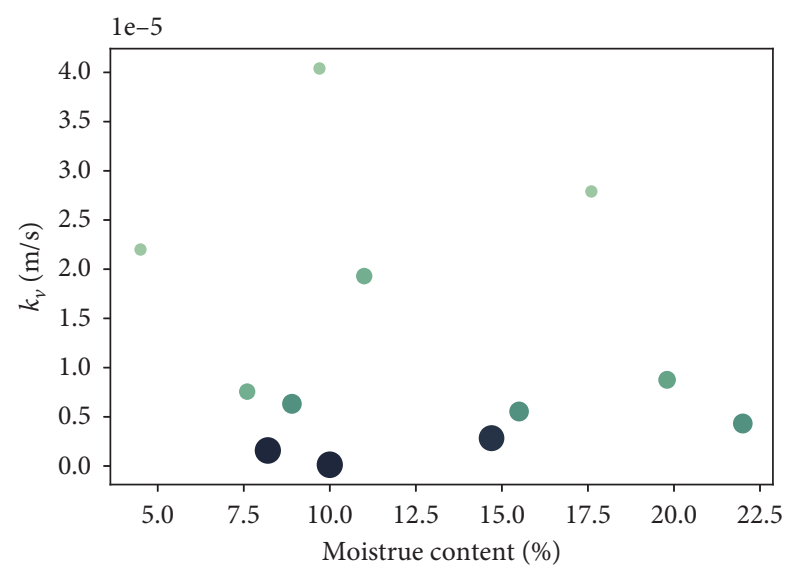

Dry density

$\begin{array}{ll}1.25 & 1.41 \\ 1.33 & 1.59 \\ 1.36 & 1.61\end{array}$

(b)

FIgURE 9: Scatter diagram between permeability coefficient and water content. (a) The intact loess. (b) The remolded loess.

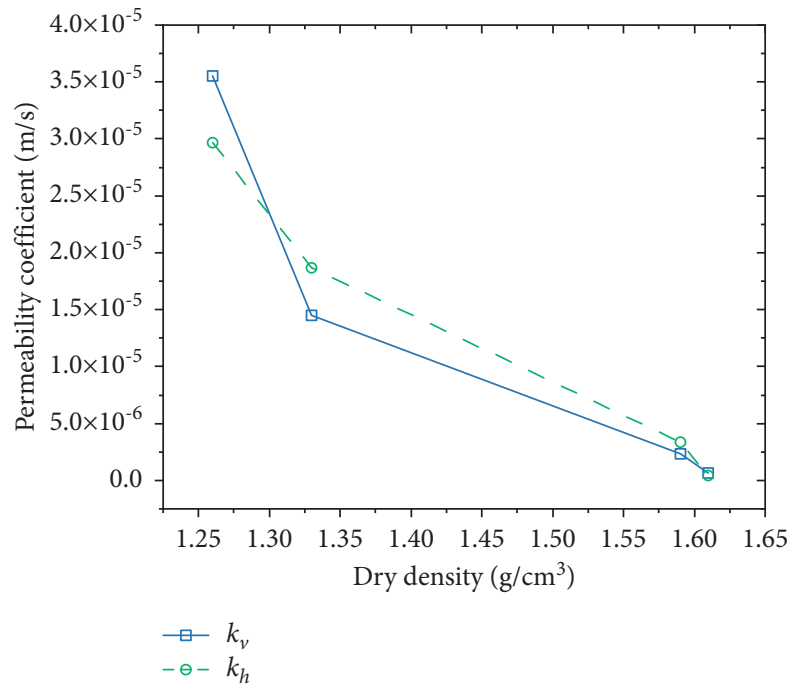

(a)

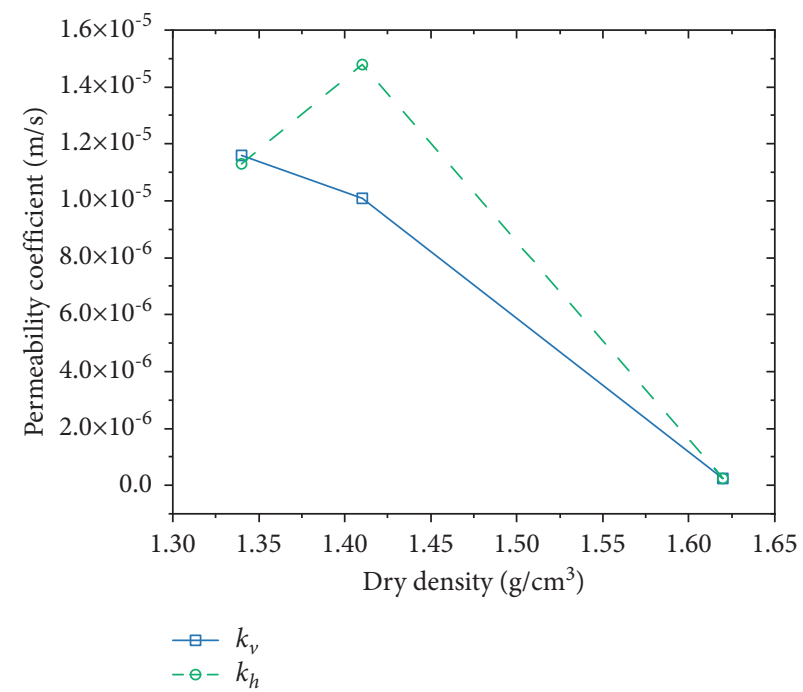

(b)

FIgURE 10: Relationship between permeability coefficient and dry density of the intact loess. (a) $\omega=10 \%$. (b) $\omega=15 \%$.

close. The permeability coefficient decreases with the increase of dry density, and the reduction rate decreases gradually. In remolded soil, water content has little effect on the change law of permeability.

Figures 12 and 13 show the scatter distribution of permeability coefficient and dry density of undisturbed soil and remolded soil, respectively. In Figure 12(a), the horizontal permeability coefficient generally meets a negative correlation with the dry density. When the dry density is small, the higher the water content, the greater the permeability. However, when the dry density is greater than $1.40 \mathrm{~g} / \mathrm{cm}^{3}$, the increase of water content will inhibit the permeability. The same variation law is also shown in the scatter diagram of the vertical permeability coefficient in Figure 12(b). The distribution of permeability coefficient of remolded soil is shown in Figure 13. Generally, the permeability coefficient will decrease with the increase of dry density. When the dry density is small, the reduction rate is large, and when the dry density is greater than $1.40 \mathrm{~g} / \mathrm{cm}^{3}$, the change rate tends to be flat.

The structural performance of loess is relatively significant, and the dry density can directly reflect the tightness of the loess pore structure. Therefore, to a great extent, the permeability will be affected by dry density. The natural structure of undisturbed loess makes it have obvious anisotropy, resulting in the difference of vertical and horizontal 


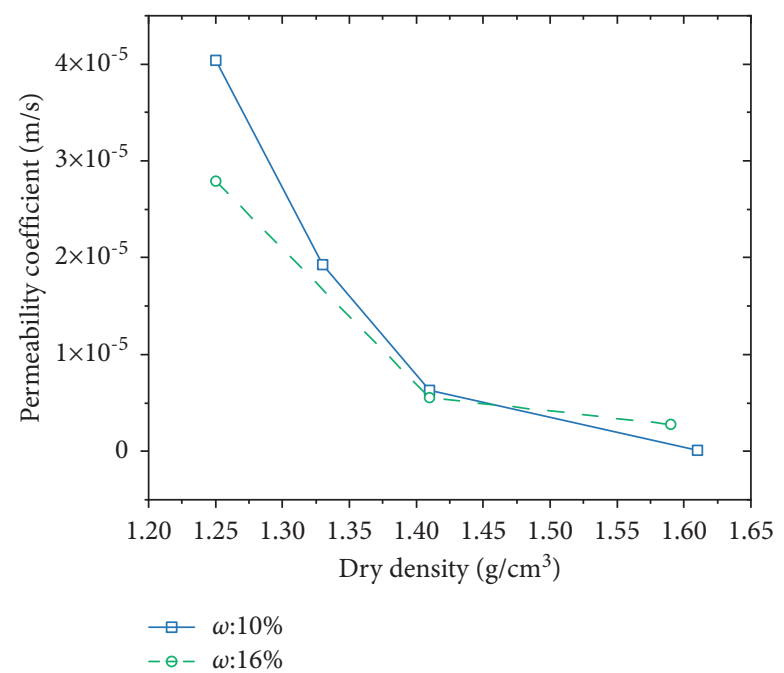

FIGURE 11: Relationship curve between permeability coefficient and dry density of remolded loess with different water contents.

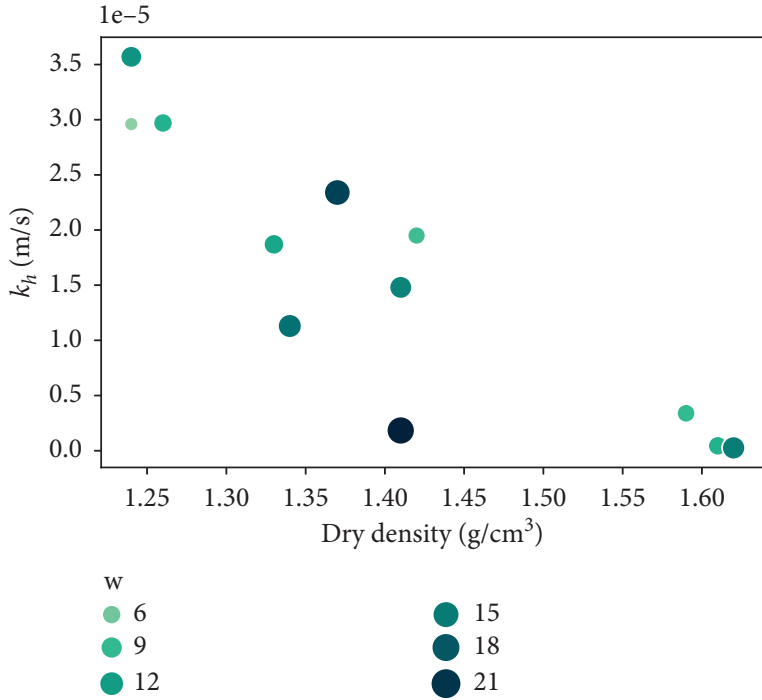

(a)

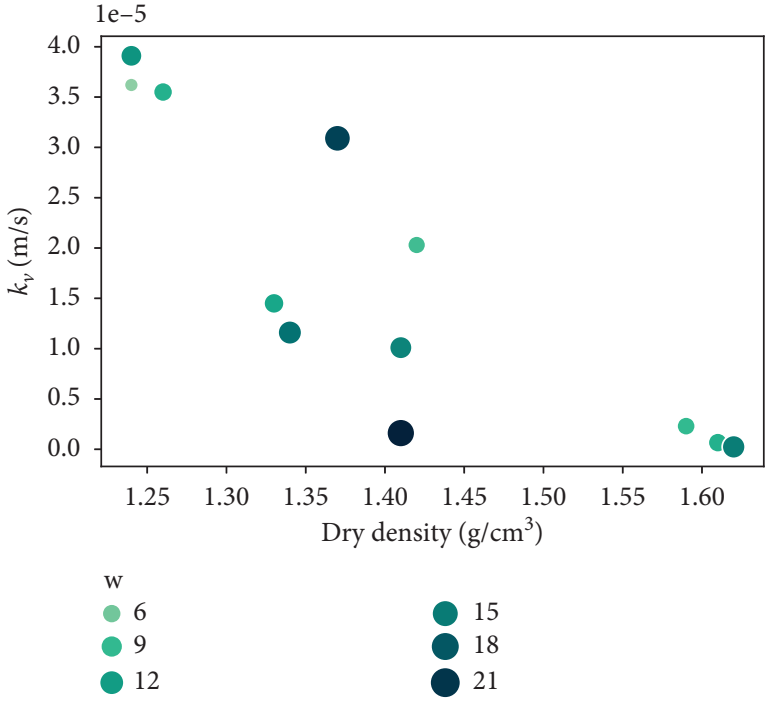

(b)

Figure 12: Relationship curve between permeability coefficient and dry density of the intact loess under different water contents. (a) Horizontal permeability coefficient. (b) Vertical permeability coefficient.

permeability, which will be reflected under different dry densities. Remolded loess is damaged due to its natural structure, but in the compaction process, soil particles will form structure again and also have structural performance. The tightness between particles is the most direct influence on permeability. Whether undisturbed loess or remolded loess, the effect of dry density on permeability is more direct. The essential reason is that the tightness of soil particle skeleton structure determines the number of effective seepage channels.

\section{Discussion}

Loess has obvious structure and water sensitivity. The pore structure directly determines the relevant hydraulic properties of loess. There is a close relationship between permeability and loess structure. The dry density and moisture content of the soil are the basic physical parameters of soil. Both of them will affect the structure and lead to the change of permeability. On the one hand, the size of dry density can reflect the tightness of the loess pore structure and directly affect the permeability. The greater the dry density, the lower the permeability. On the other hand, the moisture content is not a structural parameter of soil, and it is equivalent to external influencing factors. However, the existence of water content will change the properties of cement between soil particles. Cement mainly exists between soil particle skeletons and plays the role of filler. Under different water contents, the loess structure will change, resulting in the change of permeability. In order to determine the coupling relationship between permeability and the two, it is necessary to further consider the differences in 


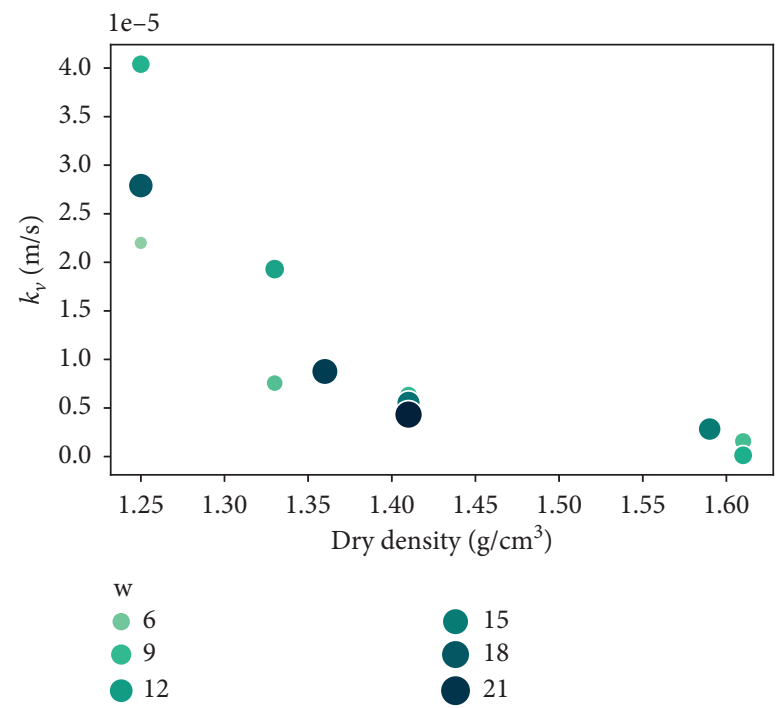

FIGURE 13: Scatter plot of permeability coefficient of remolded loess.

the influence law of pore water on cement properties under different pore structure states, which requires the summary and analysis of a large number of test data.

\section{Conclusions}

Through the permeability test of the intact loess and remolded loess in Lanzhou New Area, the saturated permeability test of loess under different dry densities and different water contents is carried out, and the influence law of two factors on loess permeability is studied and analyzed. The main research conclusions are as follows:

(1) The structural characteristics of the intact loess make the permeability of natural loess anisotropic, and the anisotropy of permeability will be reflected under different pore structures and water contents. In practical engineering, the change of seepage field distribution caused by this characteristic needs to be considered.

(2) Under different dry densities, the influence of water content on permeability is different. When the dry density is small and the pore structure is loose, the influence of the increase of water content on permeability is low, while when the pore structure of loess is compact, the inhibition of the increase of water content on permeability is more obvious.

(3) Whether intact loess or remolded loess, there is a negative correlation between dry density and loess permeability. In order to achieve the purpose of antiseepage in the project, it is necessary to control the optimal water content of the soil, so as to ensure the maximum dry density and reduce the permeability of the soil.

\section{Data Availability}

The data used to support the findings of this study are available from the corresponding author upon request.

\section{Conflicts of Interest}

The authors declare that they have no conflicts of interest regarding the publication of this study.

\section{Acknowledgments}

This study was supported by the Key Research and Development plan of Gansu Province (no. 21YF5FA085).

\section{References}

[1] W Bao-Ping and Y Ya-Jing, "Influence of structure on shear characteristics of the unsaturated loess in Lanzhou, China," Engineering Geology, vol. 168, pp. 46-58, 2014.

[2] L. Pan, J.-G. Zhu, and Y.-F. Zhang, "Evaluation of structural strength and parameters of collapsible loess," International Journal of Geomechanics, vol. 21, no. 6, 2021.

[3] Y. Fu, Z. Gao, Y. Hong, T. Li, and A. Garg, "Destructuration of saturated natural loess: from experiments to constitutive modeling," International Journal of Damage Mechanics, vol. 30, no. 4, pp. 575-594, 2021.

[4] L. Xu, M. R. Coop, M. Zhang, and G. Wang, "The mechanics of a saturated silty loess and implications for landslides," Engineering Geology, vol. 236, no. 29-42, 2018.

[5] L. Xu, C. Gao, T. Lan, J. Lei, and L. Zuo, "Influence of grading on the compressibility of saturated loess soils," Géotechnique Letters, vol. 10, no. 2, 2020.

[6] L. Xu, T.-gang Lan, and Q.-yi Mu, "Effects of structure on the compression behavior of unsaturated loess," International Journal of Geomechanics, vol. 21, no. 4, 2021.

[7] W.-tong Tian, J.-hua Dong, J.-jie Sun, and Bo Yang, "Experimental study on main physical parameters controlling shear strength of unsaturated loess," Advances in Civil Engineering, vol. 2021, Article ID 6652210, 11 pages, 2021.

[8] J. Li, S. Shao, and S. Shao, "Collapsible characteristics of loess tunnel site and their effects on tunnel structure," Tunnelling and Underground Space Technology, vol. 83, pp. 509-519, 2019.

[9] Y. Liu and H. Lai, "Load characteristics of tunnel lining in flooded loess strata considering loess structure," Advances in 
Civil Engineering, vol. 2019, Article ID 3731965, 13 pages, 2019.

[10] Y. Zhang, Z. Hu, L. Li, and Z. Xue, "Improving the structure and mechanical properties of loess by acid solutions - an experimental study," Engineering Geology, vol. 244, pp. 132$145,2018$.

[11] Q. Lv, C. Chang, B. Zhao, and B. Ma, "Loess soil stabilization by means of $\mathrm{SiO} 2$ nanoparticles," Soil Mechanics and Foundation Engineering, vol. 54, no. 6, pp. 409-413, 2018.

[12] W. Zhang, A. Guo, and L. Cheng, "Effects of cyclic freeze and thaw on engineering properties of compacted loess and limestabilized loess," Journal of Materials in Civil Engineering, vol. 31, no. 9, 2019.

[13] J. Xu, R. Chang, S. Wang, J. Gao, and X. Zhou, "Permeability and microstructure of a saline intact loess after dry-wet cycles," Advances in Civil Engineering, vol. 2021, Article ID 6653697, 18 pages, 2021.

[14] P. Xu, Q. Zhang, H. Qian, M. Guo, and F. Yang, "Exploring the geochemical mechanism for the saturated permeability change of remolded loess," Engineering Geology, vol. 284, 2021.

[15] Bo Hong, Xi-an Li, Li Wang, and L.-cui Li, "Temporal variation in the permeability anisotropy behavior of the Malan loess in northern Shaanxi Province, China: an experimental study," Environmental Earth Sciences, vol. 78, no. 15, 2019.

[16] H. Yan-zhou, W Tie-hang, J Xin, C Lei, and L Jiang-le, "Experimental study on the saturated compacted loess permeability under K-0 consolidation," Advances in Civil Engineering, vol. 2020, Article ID 1426485, 16 pages, 2020.

[17] J. Liu, X. a. Li, Q. Xue, and Z. Guo, "Experimental study on air permeability and microscopic mechanism of intact and remolded Malan loess, Loess Plateau, China," Bulletin of Engineering Geology and the Environment, vol. 79, no. 8, pp. 3909-3919, 2020.

[18] C. Chen, D. Zhang, and J. Zhang, "Influence of stress and water content on air permeability of intact loess," Canadian Geotechnical Journal, vol. 54, no. 9, pp. 1221-1230, 2017.

[19] Y.-n. Wei, W. Fan, N. Yu, L.-s. Deng, and T. Wei, "Permeability of loess from the South Jingyang Plateau under different consolidation pressures in terms of the threedimensional microstructure," Bulletin of Engineering Geology and the Environment, vol. 79, no. 9, pp. 4841-4857, 2020.

[20] Y. Zhang, H. Qian, K. Hou, and W. Qu, "Investigating and predicting the temperature effects of permeability for loess," Engineering Geology, vol. 285, 2021.

[21] P. Xu, Q. Zhang, H. Qian, and W. Qu, "Effect of sodium chloride concentration on saturated permeability of remolded loess," Minerals, vol. 10, no. 2, 2020.

[22] L.-t. Zhan, Q.-w. Qiu, W.-j. Xu, and Y.-m. Chen, "Field measurement of gas permeability of compacted loess used as an earthen final cover for a municipal solid waste landfill," Journal of Zhejiang University - Science, vol. 17, no. 7, pp. 541-552, 2016.

[23] Y. Wu, J. Cui, J. Huang, W. Zhang, N. Yoshimoto, and L. Wen, "Correlation of critical state strength properties with particle shape and surface fractal dimension of clinker ash," International Journal of Geomechanics, vol. 21, no. 6, Article ID 04021071, 2021.

[24] B. Bai, R. Zhou, G. Cai, W. Hu, and G. Yang, "Coupled thermo-hydro-mechanical mechanism in view of the soil particle rearrangement of granular thermodynamics," Computers and Geotechnics, vol. 137, 2021.
[25] B. Bai, Q. Nie, Y. Zhang, X. Wang, and W. Hu, "Cotransport of heavy metals and $\mathrm{SiO} 2$ particles at different temperatures by seepage," Journal of Hydrology, vol. 597, 2021.

[26] B. Yuan, M. Sun, Y. Wang, L. Zhai, Q. Luo, and X. Zhang, "Full 3D displacement measuring system for 3D displacement field of soil around a laterally loaded pile in transparent soil," International Journal of Geomechanics, vol. 19, no. 5, Article ID 04019028, 2019.

[27] B. Yuan, Z. Li, Z. Su, Q. Luo, M. Chen, and Z. Zhao, "Sensitivity of multistage fill slope based on finite element model," Advances in Civil Engineering, vol. 2021, Article ID 6622936, 13 pages, 2021.

[28] B. Yuan, Z. Li, Z. Zhao, H. Ni, Z. Su, and Z. Li, "Experimental study of displacement field of layered soils surrounding laterally loaded pile based on transparent soil," Journal of Soils and Sediments, vol. 21, no. 9, pp. 3072-3083, 2021.

[29] B Yuan, Z Li, Y Chen et al., "Mechanical and microstructural properties of recycling granite residual soil reinforced with glass fiber and liquid-modified polyvinyl alcohol polymer," Chemosphere, vol. 286, 2022. 